\title{
Blazing The Trail For Astronomy Education Research
}

\author{
Janelle M. Bailey, Ph.D., Temple University, USA \\ Doug Lombardi, Ph.D., Temple University, USA
}

\begin{abstract}
Education research has long considered student learning of topics in astronomy and the space sciences, but astronomy education research as a sub-field of discipline-based education research is relatively new. Driven by a growing interest among higher education astronomy educators in improving the general education, introductory science survey course for non-science majoring undergraduates ("ASTRO 101"), contemporary astronomy education research is led by scholars with significant expertise in astronomy content. In this review, we outline the recent history of the growing field of discipline-based astronomy education research by analyzing graduate degrees earned, faculty involved, and major milestones, such as the appearance of archival, peer-reviewed professional journals. Astronomy education research as a field of discipline-based education research has made notable strides in the past few decades that distinguish it from the K-12 education research realm, and, in spite of some setbacks, continues to move forward as a growing and vibrant community of scholars.
\end{abstract}

Keywords: Astronomy Education; History of Discipline-Based Education Research; ASTRO 101

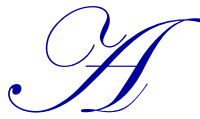

stronomy is one of the oldest scientific fields, yet it continues to capture the imagination of the young and old alike. It is one of the few-perhaps the only-science in which there is a sizeable population of amateurs who are able to contribute in meaningful ways to the growth of the field. This is exemplified by the American Association of Variable Star Observers (AAVSO), founded as a way of bringing together amateur astronomers to coordinate observing efforts across the country and, eventually, the globe. Professional astronomers frequently use data from the AAVSO to support their own research. Citizen science projects, such as SETI@Home and Galaxy Zoo (Raddick et al., 2010), have expanded the reach of astronomy to even more people; similar projects in other disciplines are also generating public excitement, especially with the Internet making participation easier than ever (e.g., Audubon's Christmas Bird Count or Boston Museum of Science's Firefly Watch). Nearly anyone can contribute to citizen science projects; that is, in fact, the goal. The same is not true for professional or academic research areas, where appreciable education and experience is required in order to be considered a scholar in the field (Mayer, 1992). In the past, there was a generally accepted distinction between what was considered education research and traditional scientific research; one need only look at the collegiate departmental home of the scholar to identify in what category one's research was situated. This is no longer the case, as science content experts (e.g., astronomers) are beginning to take on larger roles doing education research in their fields.

The National Research Council's Committee on the Status, Contributions, and Future Directions of Discipline-Based Education Research (2012) defines discipline-based educational research (DBER) as "systematically investigating learning and teaching in science and engineering and providing a robust evidence based on which to base practice" (p. 8). In this sense, DBER is differentiated from traditional educational research by its focus on primarily undergraduate teaching and learning and by the background of the researcher who is conducting it. Foremost as the principal context for astronomy education research (AER) is the general education, introductory astronomy survey course for non-science majoring undergraduate college students, colloquially known as "ASTRO 101" in the United States. Furthermore, DBERers often share their work through journals and conferences that are of interest to and attended by content-area experts (as opposed to education experts). In the case 
of AER, this includes journals such as, but not limited to, the Journal of Astronomy \& Earth Science Education Research (JAESE), the recently closed Astronomy Education Review (which we will abbreviate as AER* to distinguish it from the general discipline) and American Journal of Physics (AJP) as well as conferences hosted by the American Astronomical Society (AAS), the Astronomical Society of the Pacific (ASP), and the American Association of Physics Teachers (AAPT).

Our purpose in writing this review is to analyze a brief history of relatively recent developments of AER within the larger landscape of the rapidly growing DBER field in order to contribute to an earnest dialogue about productive and meaningful research directions. In other words, this reflection on the past may be one tool used to help guide AER's future path. We first make a distinction between AER and related fields, then discuss the some of the people involved in AER (with sincere apologies to those scholars not described here). Next we revisit important milestones and support mechanisms, including professional organizations and journals, that have been created in the history of AER. Finally, we draw conclusions about the health of the field. We will not extensively discuss the content or results of AER, as that has been and will be discussed in detail elsewhere (Bailey, 2011; Bailey \& Lombardi, 2015-in preparation; Bailey \& Slater, 2003).

\section{Prelude: AER as Distinct from PER and GER}

Why does AER - a relatively small field compared to other DBER disciplines-warrant separate attention? Might not AER be considered as following in the footsteps of physics education research (PER), in both topic and research design, and therefore, just a sub-topical area? At the university level, astronomy faculty are most often housed within physics departments; astronomy-only departments are quite rare. Much less common are astronomy faculty within geosciences departments, and such housing tends to occur in smaller schools. Even in institutions in which there is no astronomer, physicists may be asked to teach an ASTRO 101 course. This close connection between physics and astronomy coursework and faculty has led to a close following of PER by AER.

That being said, AER also has some distinct and important differences from PER or geoscience education research (GER) that are worth considering. Although there are more students taking introductory physics or physical science than introductory astronomy (AIP Statistical Research Center, 2013; Mulvey \& Nicholson, 2014), ASTRO 101 courses are often aimed at satisfying general education requirements and so are taken by a large number of undergraduate students in the United States who are not majoring in science fields, often as their only or last science class (Fraknoi, 2001; Lawrenz, Huffman, \& Appeldoorn, 2005). Furthermore, many ASTRO 101 courses are often taught with little mathematics; contrast this with introductory physics, which is usually described, at least informally, by the level of mathematics required (e.g., algebra-based versus calculus-based). As a result, PER rapidly encompassed the many different levels of undergraduate physics education, and now extends into graduate education in physics. This instructional landscape is very different from that of astronomy, where few institutions even have astronomy majors (Cabanela \& Partridge, 2002), and little research is being conducted on higher-level coursework. Another difference is that astronomy courses may or may not be held with associated laboratory sections, whereas labs are the norm for introductory physics, providing another rich research area for PER. Finally, AER has benefitted from funding from NASA through its various education and public outreach (E/PO) programs. This is in addition to traditional research funding, such as that provided by the NSF, which supports PER.

What about GER? Introductory geoscience courses, widely defined, are taken by more students than ASTRO 101 (American Geological Institute Geoscience Workforce Program, Martinez, \& Baker, 2006; Mulvey \& Nicholson, 2014). Like between PER and AER, there is certainly an overlap of some content with GER. However, there are some critical differences. For example, field experiences are an important part of geoscience education (Piburn, van der Hoeven Kraft, \& Pacheco, 2011), but such experiences are not generally within the purview of introductory astronomy courses, other than the occasional star party or telescope open house. Additionally, astronomy typically is considered part of earth science in $\mathrm{K}-12$, but is more closely associated with physics at the tertiary level (hence, the faculty placement issues as described above). These differences between AER, PER, and GER, in addition to the fields' historical developments as viewed through the researchers involved, support viewing AER as a distinct discipline. 


\section{WHO ARE ASTRONOMY EDUCATION RESEARCHERS?}

\section{AER Trailblazers}

When thinking about the origins of AER as a discipline-based education research field (as opposed to being a subset of traditional education research), we can look both at the first doctoral students whose dissertations were based upon AER and at faculty who earned degrees in science fields but later became interested in astronomy education as a research line. Three early doctoral students exemplify the range in time and foci of early AER dissertations that have strong similarities to DBER. David Targan earned his Ph.D. from the University of Minnesota in 1988. The Assimilation and Accommodation of Concepts in Astronomy (Targan, 1988) investigated ASTRO 101 students' conceptual change about lunar phases, and was guided by faculty from education, physics, and astronomy. Tim Slater's Ph.D. was granted through the Department of Geosciences at the University of South Carolina. Entitled The Effectiveness of a Constructivist Epistemological Approach to the Astronomy Education of Elementary and Middle Level In-service Teachers (Slater, 1993), this study focused on teachers' changes in knowledge, attitudes, values, and interest after a 15 -week University-based astronomy course with a constructivist pedagogical design. Rebecca Lindell completed her Ph.D. in 2001 from the University of Nebraska-Lincoln's Department of Physics and Astronomy. Enhancing College Students' Understanding of Lunar Phases (Lindell, 2001) included the design of curriculum and an associated assessment instrument for use in ASTRO 101.

Some of the earliest AER faculty at research extensive or intensive universities included Michael Zeilik, of the University of New Mexico Department of Physics and Astronomy (now retired), Phil Sadler of the HarvardSmithsonian Center for Astrophysics (CfA), and Jeff Adams and Greg Francis then of the Department of Physics at Montana State University (MSU). Zeilik had received NSF funding as early as 1992 to reform introductory astronomy courses at his institution (Zeilik, 2003). Sadler has served as the Director of the Department of Science Education within CfA since 1992. In addition to his work on astronomy assessments, Sadler famously served as the executive producer for A Private Universe (Schneps, 1989), an NSF-funded video about students' understanding of astronomical concepts. Francis had previously been involved with the University of Washington's PER group and brought that focus to MSU, with occasional forays into AER when working with Adams and Slater. The MSU group formed what was then known as the Conceptual Astronomy and Physics Education Research (CAPER) Team in 1997, with research foci by faculty and graduate students in both PER and AER. Later, Slater and Adams expanded their work beyond the confines of MSU by collaborating with Zeilik, Lindell, Beth Hufnagel (Anne Arundel Community College), Grace Deming (University of Maryland), Gina Brissenden (then University of WisconsinMadison), Christine Brick (then a NSF Post-doctoral Fellow), and others to form the Collaboration for Astronomy Education Research (CAER). The primary accomplishment of CAER was the development of the Astronomy Diagnostic Test (ADT) (Hufnagel, 2002; Hufnagel et al., 2000), which paved the way for other diagnostic instruments in AER, such as the now widely used Test Of Astronomy Standards, TOAST (Slater, 2014; Slater, Schleigh, \& Stork, 2015).

\section{Contemporary Scholars and Programs}

Slater moved to the University of Arizona's Department of Astronomy in 2001, and reestablished the CAPER Team there. This move created one of the first formal programs for graduate students to perform research with a primary focus on issues relating to astronomy education. Led by Slater and supported by then-Assistant Research Scientist and Instructor Ed Prather, doctoral students completed coursework in both education and astronomy content, or in some cases entered the program with significant coursework and experience in astronomy but needed the same in education. More than a dozen students were affiliated with the Arizona CAPER Team, most of who could be considered DBERers in their research interests, though the details of their paths may differ. CAPER also welcomed a number of post-doctoral researchers and visiting faculty who were becoming increasingly involved in AER.

Individual scholars followed suit, though affiliations varied between colleges of science or colleges of education. As non-exhaustive examples, Julia Plummer completed her doctorate from the University of Michigan in a self-designed combined program in astronomy and education, with dissertation co-chairs from each college. Similarly, Larry Krumenaker earned his doctorate from the University of Georgia's Department of Mathematics and 
Science Education, having already had considerable expertise in astronomy content through earlier degrees and teaching experience. Both Plummer's and Krumenaker's dissertations focused on astronomy issues at K-12 levels. Montana State's Department of Physics continues its PER program in which some students focus their research on astronomy-related topics; for example, Kathryn Williamson studied issues relating to gravity (Williamson, 2013; Williamson \& Willoughby, 2012; Williamson, Willoughby, \& Prather, 2013), thus bridging PER and AER. The University of Colorado at Boulder's Department of Astrophysical and Planetary Sciences is following the example of the Department of Physics' strong PER doctoral program; Colin Wallace was a student in the former department studying cosmology education (Wallace, 2011).

Slater (2008) described what he calls "the first big wave of astronomy education research dissertations" (p.1), completed between 2006 and 2008 (several in association with the University of Arizona CAPER Team, and others by individual researchers described above). He claimed that these dissertations, in combination with the success of $A E R^{*}$ and support of DBER by professional societies such as the AAS and the American Physical Society, "clearly signal that astronomy education research is a healthily growing discipline in and of itself" (Slater, 2008, p. 2). DBER (AER) dissertations now include those listed in Table 1 below. In creating Table 1, we used the following criteria: (a) the dissertation focused on a topic that is strongly associated with astronomy, (b) the dissertation was within an educational context (i.e., K-12, undergraduate, graduate, or informal), and (c) at least one of the dissertation advisors was a college of science faculty who has taught astronomy. Additionally, Table 1 lists dissertations that fell outside the scope of at least one of these criteria. We also included those who self-identify as AERers, either currently or at the time when preparing their dissertation. Contrastingly, Table 1 does not include dissertations that were conducted under the auspices of traditional education programs by students who, in general, did not have significant background in or connections with astronomy, even though an astronomy topic was highlighted in the dissertation. Finally, we acknowledge that Table 1 is probably not exhaustive due to the burgeoning nature of the field. 
Table 1. Sample of AER Dissertations Completed in Recent Years (Non-Exhaustive)

\begin{tabular}{|c|c|c|c|}
\hline Name & Year & School & Title \\
\hline David Hudgins & 2005 & University of South Africa & $\begin{array}{l}\text { Investigation of the effects of ranking tasks on student } \\
\text { understanding of key astronomy topics }\end{array}$ \\
\hline Janelle Bailey & 2006 & University of Arizona & $\begin{array}{l}\text { Development of a concept inventory to assess students' } \\
\text { understanding and reasoning difficulties about the properties } \\
\text { and formation of stars }\end{array}$ \\
\hline $\begin{array}{l}\text { Erin Bardar } \\
\text { (Weeks) }\end{array}$ & 2006 & Boston University & $\begin{array}{l}\text { Development and analysis of spectroscopic learning tools and } \\
\text { the Light and Spectroscopy Concept Inventory for introductory } \\
\text { college astronomy }\end{array}$ \\
\hline John Keller & 2006 & $\begin{array}{l}\text { University of Arizona } \\
\text { (Department of Planetary } \\
\text { Sciences) }\end{array}$ & $\begin{array}{l}\text { Part I. Development of a concept inventory addressing students' } \\
\text { beliefs and reasoning difficulties regarding the greenhouse } \\
\text { effect. Part II. Distribution of chlorine measured by the Mars } \\
\text { Odyssey Gamma Ray Spectrometer. }\end{array}$ \\
\hline Julia Plummer & 2006 & University of Michigan* & Students' development of astronomy concepts across time \\
\hline Pebble Richwine & 2007 & University of Arizona & $\begin{array}{l}\text { The impact of authentic science inquiry experiences studying } \\
\text { variable stars on high school students' knowledge and attitudes } \\
\text { about science and astronomy and beliefs regarding the nature of } \\
\text { science }\end{array}$ \\
\hline Erin Dokter & 2008 & University of Arizona & $\begin{array}{l}\text { "It's the journey": Exploring the consequences of a professional } \\
\text { development workshop for college astronomy faculty }\end{array}$ \\
\hline Larry Krumenaker & 2008 & University of Georgia & $\begin{array}{l}\text { The status and makeup of the U.S. high school astronomy } \\
\text { course in the era of No Child Left Behind }\end{array}$ \\
\hline Audra Baleisis & 2009 & University of Arizona & $\begin{array}{l}\text { Joining a discourse community: How graduate students learn to } \\
\text { speak like astronomers }\end{array}$ \\
\hline Erik Brogt & 2009 & University of Arizona & $\begin{array}{l}\text { Pedagogical and curricular thinking of professional astronomers } \\
\text { teaching the Hertzsprung-Russell diagram in introductory } \\
\text { astronomy courses for non-science majors }\end{array}$ \\
\hline Sanlyn Buxner & 2010 & University of Arizona & $\begin{array}{l}\text { Exploring the impact of science research experiences for } \\
\text { teachers: Stories of growth and identity }\end{array}$ \\
\hline Kendra Sibbernsen & 2010 & Cappella University & $\begin{array}{l}\text { The impact of collaborative groups versus individuals in } \\
\text { undergraduate inquiry-based astronomy laboratory learning } \\
\text { exercises }\end{array}$ \\
\hline Stephanie Slater & 2010 & University of Arizona & $\begin{array}{l}\text { The educational function of an astronomy REU program as } \\
\text { described by participating women }\end{array}$ \\
\hline Daniel Lyons & 2011 & University of Wyoming & $\begin{array}{l}\text { Impact of backwards faded scaffolding approach to inquiry- } \\
\text { based astronomy laboratory experiences on undergraduate non- } \\
\text { science majors' views of scientific inquiry }\end{array}$ \\
\hline Colin Wallace & 2011 & $\begin{array}{l}\text { University of Colorado } \\
\text { (Department of } \\
\text { Astrophysical \& Planetary } \\
\text { Sciences) }\end{array}$ & $\begin{array}{l}\text { An investigation into introductory astronomy students' } \\
\text { difficulties with cosmology, and the development, validation, } \\
\text { and efficacy of a new suite of cosmology lecture-tutorials }\end{array}$ \\
\hline Matthew Wenger & 2011 & University of Arizona & $\begin{array}{l}\text { Free-choice family learning experiences at informal astronomy } \\
\text { observing events }\end{array}$ \\
\hline Inge Heyer & 2012 & University of Wyoming & $\begin{array}{l}\text { Establishing the empirical relationship between non-science } \\
\text { majoring undergraduate learners' spatial thinking skills and } \\
\text { their conceptual astronomy knowledge }\end{array}$ \\
\hline Kathryn Williamson & 2013 & $\begin{array}{l}\text { Montana State University } \\
\text { (Department of Physics) }\end{array}$ & $\begin{array}{l}\text { Development and calibration of a concept inventory to measure } \\
\text { introductory college astronomy and physics students' } \\
\text { understanding of Newtonian gravity }\end{array}$ \\
\hline Debra Stork & 2014 & University of Wyoming & $\begin{array}{l}\text { Contemporary discipline-based astronomy education research } \\
\text { study of K-12 teachers' astronomy knowledge using the Test Of } \\
\text { Astronomy STandards }\end{array}$ \\
\hline
\end{tabular}

Note: Except where noted, degrees were granted through a college of education program, but usually with considerable background or coursework in astronomy content. *indicates a joint college of science-college of education program.

Slater again moved the CAPER Team in 2008, this time to the University of Wyoming. A new group of doctoral students has continued to expand the AER community, with the earliest graduate in 2011. At the University of Arizona, Prather became director of the Center for Astronomy Education (CAE, originally established in 2003 by 
Slater), which among other things offers teaching workshops for astronomy faculty (Brissenden, Prather, Slater, Greene, \& Thaller, 2007), and became the second faculty member to be awarded tenure at UA based on a scholarly record of AER.

But what about faculty who are interested in AER, but who already have their doctorate in astronomy? There are an increasing number of resources that can help astronomers move into AER without going through another degree program. S. J. Slater, T. F. Slater, Heyer, and Bailey (2015) published a primer on doing AER and have conducted workshops on this topic at AAS and AAPT meetings. The CAE CATS program has led to a collaborative mentorship program for AER-interested (but novice) faculty by more experienced AERers (Brissenden, Impey, Prather, Lee, \& Collaboration of Astronomy Teaching Scholars, 2010; Brissenden, Impey, Prather, Lee, \& Duncan, 2009). Brogt and colleagues provided an important series of articles that outline ethical and regulatory issues surrounding research involving human subjects (Brogt, Dokter, \& Antonellis, 2007; Brogt, Dokter, Antonellis, \& Buxner, 2007; Brogt, Foster, Dokter, Buxner, \& Antonellis, 2008). Brogt (2007) also described his own experiences in "becoming a hybrid researcher" (p. 1) who studies both astronomy and astronomy education. These resources serve as informal training opportunities for professional astronomers who have become interested in conducting AER in addition to or instead of traditional scientific research. This again parallels the example of PER faculty who created a series of workshops and guiding documents for PER novices (viz., http://www.compadre.org/per/per reviews/volume2.cfm, and references therein).

\section{Visualizing the Field}

One of the challenges in defining DBER is that there is an increasing amount of collaboration between disciplines, making it difficult to demarcate differences should they be needed. Thus in an attempt to understand who is doing AER, consider Figure 1 below. To create this schematic, we defined "Astronomy Scores" and "Education Scores" for about a dozen people who have been associated with AER. These scores are loosely based upon number of degrees in the field (education vs. astronomy or related fields such as physics or geoscience) and research and teaching experience in those same fields. We have further defined three regions on the graph, based in part on our own knowledge of these scholars' research interests, publication venues, and experience. Region 1 comprises what we consider traditional educational research (which might include science education, cognitive science, and educational psychology, for example). Science - specifically astronomy, perhaps with some physicsresearch dominates Region 3. Finally, Region 2 includes people who have significant expertise in astronomy and are conducting DBER as defined above. As AER continues to grow, and the experiences of DBERers grow within it, we would expect to see a trajectory toward the upper right of the figure. The research topics and methods used by these researchers are not clearly demarcated, though in general there tends to be a trend toward the topics being relatively more aligned to what the researcher's colleagues and home department would find of interest. (In other words, those researchers whose home is an education college may focus more on topics relating to astronomy in K-12 settings or teacher education, whereas those in a college of science might be more aligned with our definition of AER with an ASTRO 101 focus.) However, this is in no way limiting or restricted in this regard. 
Figure 1. A schematic representation of scholars conducting astronomy education research.

Astronomy and education scores are based upon degrees earned plus teaching and research experience in the respective fields. Colors indicate the type of academic home of the current position held by the individual. Regions describe different areas of research focus: (1) traditional education research, (2) AER as defined in this paper, and (3) traditional astronomy research.

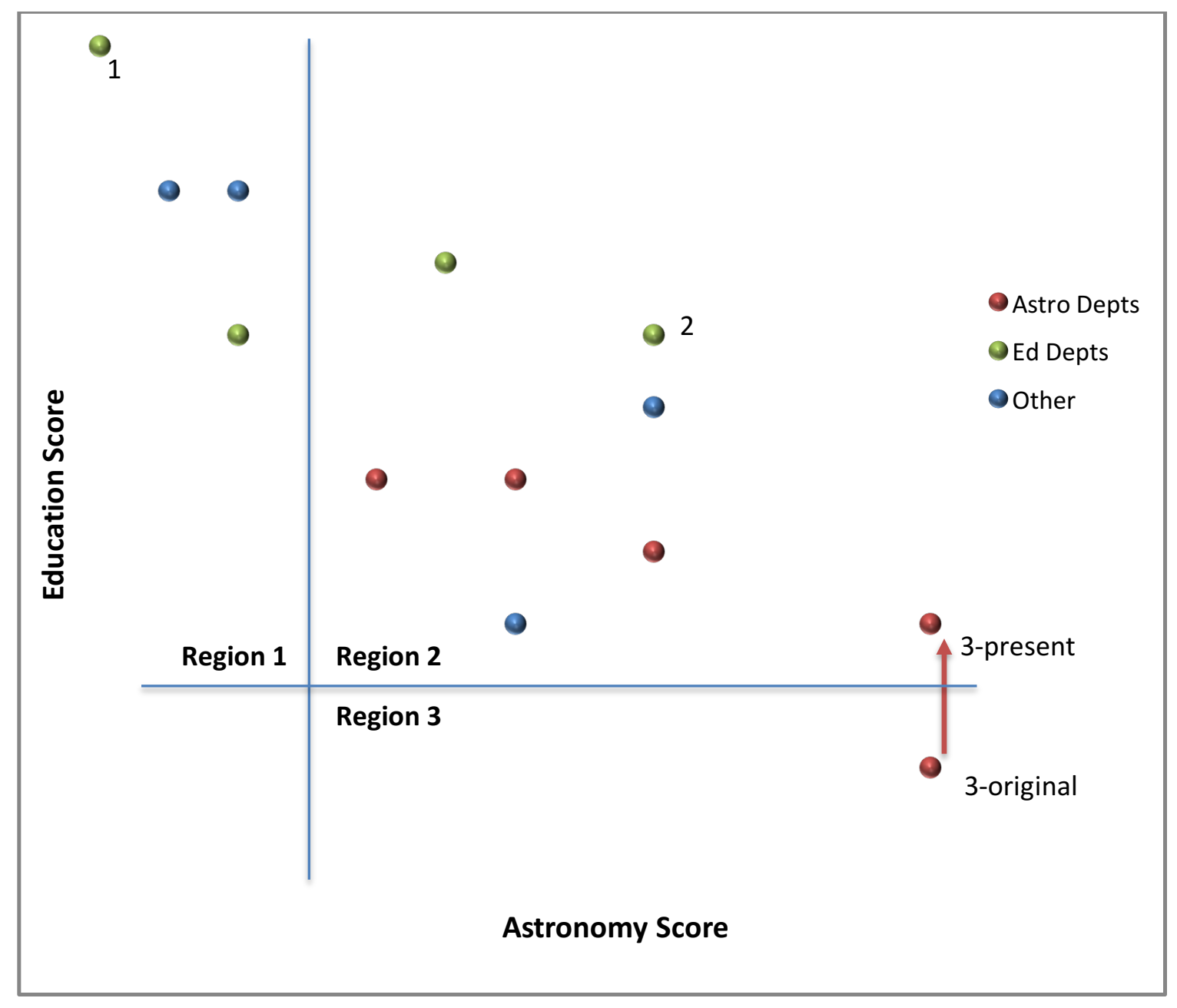

Three of the points on are labeled as examples. As a starting point, consider Point 2, a well-known AERer who has degrees, scholarship, and teaching experiences in astronomy and science education in about equal measure. Contrast his position on Figure 1 with two others. First, on the upper left is Point 1, a respected and oft-cited cognitive psychologist who frequently investigates children's understanding of astronomical topics, publishing those studies in educational psychology and cognitive science journals, but who has little formal background in astronomy. On the lower right are two points (3-original and 3-present). A respected cosmologist, this person has developed an interest in AER. At the time of this original analysis (Bailey, 2011), she had not yet published research in the field (though she had presented at professional conferences); this point is 3-original. She has since published multiple AER papers, resulting in the point 3-present. Her trajectory is represented by the arrow as she gained experience in publishing, with her Education Score increasing and thus she has moved into Region 2.

Figure 1 is intended to provide a starting point for our discussion and is certainly not comprehensive. Rather, it is an abstraction of the challenge in defining AER as a field because of the wide-ranging expertise brought to bear on understanding astronomy education. 


\section{Milestones and the Changing Status of the Field}

In many regards, AER has followed in the footsteps of PER, with an approximately 20 -year lag. The most important milestones have occurred since the late 1990s, and largely in the $21^{\text {st }}$ century. Slater was the first faculty member whose exclusive focus was on AER to earn tenure at a large, research-extensive Ph.D. granting institution (2003, Department of Astronomy, University of Arizona), having begun as a research associate professor funded by grants at Montana State University. Prather's path began as a post-doctoral research fellow at Montana State, proceeding to an assistant research scientist at Arizona. He later moved into a tenure-track position, and in 2011, earned tenure in Arizona's Astronomy Department. These are but two examples of a growing field.

A number of support systems have been established in recent years that are reflective of a growing respect for AER as a valued field. These demonstrate the value of AER to the broader astronomy research community, in addition to providing support for those engaged in educational research. For example, professional organizations have established committees and published position statements relating to astronomy education and, later, astronomy education research. The AAS created the Astronomy Education Board in 1996, with the new term starting in January 1997 (American Astronomical Society, 2008). AAS also passed a resolution "In Support of Research in Astronomy Education" in 2002 (American Astronomical Society, n.d.). AAS typically has multiple oral sessions and poster contributions relating to education and outreach at each of their two conferences per year. AAPT has an area committee, first known as the Committee on Astronomy Education but changed in 2004 to the Committee on Space Science and Astronomy, which regularly contributes both AER and astronomy content to the organization's two annual conference programs and wider interests. This committee was first formed in 1983significantly earlier than any of these other milestones - specifically with the intent of helping physicists who were tasked with teaching astronomy and astrophysics courses (Dukes Jr., 1990; M. B. Monroe, personal communication, February 14, 2011). Moreover, the International Astronomical Union has formally established a Working Group on Astronomy Education Research (http://www.caperteam.com/iau) and supporting a 2016 IAU Symposium on Astronomy Education Research in Heidelberg.

One area in which AER leapt ahead of PER was in the establishment of a dedicated journal for the field, Astronomy Education Review (AER*), in 2001. (Contrast this with Physical Review Special Topics-Physics Education Research (PRST-PER), which published its first issue in 2005.) Created by Sidney Wolff, then at the National Optical Astronomy Observatory, and Andrew Fraknoi of Foothills College and the Astronomical Society of the Pacific, it was supported by an Editorial Board with a wide range of expertise in astronomy education and public outreach (Fraknoi, 2015). This open-access journal contained sections entitled Research and Applications, Innovations, Resources, Commentary and News, Reviews and Excerpts, Letters to the Editor, Opportunities, and Extended Thesis/Dissertation Abstracts. AER* quickly became the primary publishing venue for research on topics of interest to ASTRO 101, though it also included research with contexts in other grade levels, associated with teacher education, and on informal education. In 2009, AAS took over the responsibility of publishing $A E R^{*}$. It was supported financially in part by the ASP and the National Science Foundation (NSF), and for a period was hosted on the American Institute of Physics (AIP)'s Scitation platform. Dr. Thomas Hockey (University of Northern Iowa) assumed the role of Editor-in-Chief on January 1, 2010, upon Wolff's retirement from the journal.

June 2013 brought an announcement from the AAS that it would close $A E R^{*}$ at the end of the year; articles remain freely available online at their original DOIs or through Portico (http://portico.org/stable?cs=ISSN 15391515). Editor Larry Krumenaker, through his Hermograph Press, created the digital-only Journal and Review of Astronomy Education and Outreach (http://jraeo.com/), but it lasted only three years. Krumenaker's The Classroom Astronomer began in 2009, aimed primarily at high school but occasionally including articles of interest to both lower and higher grade levels, and continues today. To help fill this void, Editor-in-Chief Tim Slater, along with an editorial advisory board established the Journal of Astronomy and Earth Science Education (http://www.jaese.org/) in 2014 (T. F. Slater, 2014) . Since the closure of $A E R^{*}$, publications have continued through these other venues, as well as some physics and PER-related journals such as PRST-PER and AJP. 


\section{CONCLUSIONS}

Over the last two decades, AER has begun to develop into a distinct research field, with an identity different from both PER and GER despite some overlapping interests and content. The paths taken by astronomy education researchers vary, but a theme of improving astronomy learning and teaching for the ASTRO 101 courses - which are widely taken, especially by non-science majoring undergraduate college students in the United States (Fraknoi, 2001; Lawrenz et al., 2005; Mulvey \& Nicholson, 2014)-permeates the field as a whole. Although the field has experienced some setbacks, such as with the unexpected closure of Astronomy Education Review by the American Astronomical Society, there continue to be steps forward that position AER for a strong future. This present analytical review, however, is only the beginning of a conversation that must occur within the AER community. By examining our past enterprises and what falls within the purview of AER, we can build upon the foundation of an appreciable body of research that has endeavored to improve astronomy education. The AER community must continue to focus and refine its research and analysis methods, by considering, for example, previously uninvestigated topics and longitudinal and cross age studies. By gaining a greater understanding of the cognitive mechanisms and social cultural contexts that drive astronomy learning and teaching, AER can continue to make a meaningful contribution and carve out a much-needed disciplinary niche.

\section{ACKNOWLEDGEMENTS}

This work emerged from part of a commissioned report for the National Research Council's Committee on the Status, Contributions, and Future Directions of Discipline-Based Education Research. J. Bailey would like to thank Tim Slater for suggesting that effort and encouraging this updated manuscript, as well as Natalie Nielsen and Susan Singer for their generous feedback and support.

\section{AUTHOR INFORMATION}

Janelle Bailey, Ph.D. is an Associate Professor of Science Education in Temple's Department of Teaching \& Learning. Her research focuses on astronomy education as well as teacher development, and more recently issues related to teacher beliefs. She earned her Ph.D. in Teaching and Teacher Education from the University of Arizona. Dr. Bailey served as the the President-Elect of the American Association of Physics Teachers (AAPT) in 2015 and President in 2016.

Doug Lombardi, Ph.D. is an Assistant Professor of Science Education in Temple University's Department of Teaching \& Learning. His research is on the role of reasoning in conceptual change and epistemic cognition. He earned his Ph.D. in Educational Psychology from the University of Nevada, Las Vegas and is a licensed physics and mathematics teacher, with a variety of classroom, professional development, and education and public outreach experience.

\section{REFERENCES}

AIP Statistical Research Center. (2013). Recent enrollments in introductory physics courses. College Park, MD: Author.

American Astronomical Society. (2008). AAS - committees. Retrieved November 18, 2010, from http://members.aas.org/comms/edboard.cfm

American Astronomical Society. (n.d.). Council resolutions. Retrieved November 18, 2010, from $\mathrm{http}$ ///aas.org/governance/resolutions.php\#edresearch

American Geological Institute Geoscience Workforce Program, Martinez, C., \& Baker, M. A. (2006). Introductory geoscience enrollment in the United States: Academic year 2004-2005. Alexandria, VA: American Geological Institute.

Bailey, J. M. (2011). Astronomy education research: Developmental history of the field and summary of the literature [a commissioned paper for the National Research Council's Committee on the Status, Contributions, and Future Direction of Discipline-Based Education Research (DBER)]. Washington, DC: The National Academies of Sciences, Engineering, and Medicine.

Bailey, J. M., \& Lombardi, D. (2015-in preparation). AER as a discipline: A critical review. 
Bailey, J. M., \& Slater, T. F. (2003). A review of astronomy education research. Astronomy Education Review, 2(2), 20-45. doi: 10.3847/AER2003015

Brissenden, G., Impey, C., Prather, E. E., Lee, K. M., \& Collaboration of Astronomy Teaching Scholars. (2010, January). The Center for Astronomy Education (CAE) and our NSF funded CCLI Phase III Collaboration of Astronomy Teaching Scholars (CATS) Program: Updates to our new community-based model for astronomy education research. Paper presented at the 215th Meeting of the American Astronomical Society, Washington, DC.

Brissenden, G., Impey, C., Prather, E. E., Lee, K. M., \& Duncan, D. (2009, January). The Center for Astronomy Education (CAE) ushers in a new community-based model for astronomy education research with the NSF funded CCLI Phase III Collaboration of Astronomy Teaching Scholars (CATS) Program. Paper presented at the 213th Meeting of the American Astronomical Society, Long Beach, CA.

Brissenden, G., Prather, E. E., Slater, T. F., Greene, W. M., \& Thaller, M. L. (2007). The NASA Center for Astronomy Education (CAE): 2007 college astronomy teaching excellence workshops. Paper presented at the 209th Meeting of the American Astronomical Society, Seattle, WA. http://adsabs.harvard.edu/abs/2006AAS...20915705B

Brogt, E. (2007). Astronomy education: Becoming a hybrid researcher. Journal of Research Practice, 3(1), article M2. http://jrp.icaap.org/index.php/jrp/article/view/57/82

Brogt, E., Dokter, E. F., \& Antonellis, J. (2007). Regulations and ethical considerations for astronomy education research. Astronomy Education Review, 6(1), 43-49. doi: 10.3847/AER2007004

Brogt, E., Dokter, E. F., Antonellis, J., \& Buxner, S. (2007). Regulations and ethical considerations for astronomy education research II: Resources and worked examples. Astronomy Education Review, 6(2), 99-110. doi: 10.3847/AER2007021

Brogt, E., Foster, T. M., Dokter, E. F., Buxner, S., \& Antonellis, J. (2008). Regulations and ethical considerations for astronomy education research III: A suggested code of ethics. Astronomy Education Review, 7(2), 57 65. doi: 10.3847/AER2008020

Cabanela, J., \& Partridge, B. (2002). So what is the astronomy major? Astronomy Education Review, 1(2), 67-84. doi: $10.3847 /$ aer2002007

Dukes Jr., R. J. (1990). Astronomy activities of the American Association of Physics Teachers. In J. M. Pasachoff \& J. R. Percy (Eds.), The teaching of astronomy (pp. 320-321). New York, NY: Cambridge University Press.

Fraknoi, A. (2001). Enrollments in astronomy 101 courses: An update. Astronomy Education Review, 1(1), $121-123$. doi: $10.3847 /$ AER2001011

Fraknoi, A. (2015). A brief history of publishing papers on astronomy education research. Journal of Astronomy \& Earth Sciences Education, 1(1), 37-40.

Hufnagel, B. (2002). Development of the Astronomy Diagnostic Test. Astronomy Education Review, 1(1), 47-51. doi: 10.3847/AER2001004

Hufnagel, B., Slater, T. F., Deming, G. L., Adams, J. P., Adrien, R. L., Brick, C., \& Zeilik, M. (2000). Pre-course results from the Astronomy Diagnostic Test. Publications of the Astronomical Society of Australia, 17(2), $152-155$.

Lawrenz, F., Huffman, D., \& Appeldoorn, K. (2005). Enhancing the instructional environment: Optimal learning in introductory science. Journal of College Science Teaching, 34(7), 40-44.

Lindell, R. S. (2001). Enhancing college students' understanding of lunar phases. (Ph.D. dissertation), University of Nebraska-Lincoln, Lincoln, NE.

Mayer, R. E. (1992). Thinking, problem solving, cognition (2nd ed.). New York: W.H. Freeman and Company.

Mulvey, P., \& Nicholson, S. (2014). Astronomy enrollments and degrees: Results from the 2012 survey of astronomy enrollments and degrees. College Park, MD: AIP Statistical Research Center.

National Research Council. (2012). Discipline-based education research: Understanding and improving learning in undergraduate science and engineering (S. R. Singer, N. R. Nielsen, \& H. A. Schweingruber, Eds.). Washington, DC: The National Academies Press.

Piburn, M. D., van der Hoeven Kraft, K., \& Pacheco, H. (2011). A new century for geoscience education research [a commissioned paper for the National Research Council's Committee on the Status, Contributions, and Future Direction of Discipline-Based Education Research (DBER)]. Washington, DC: The National Academies of Sciences, Engineering, and Medicine. 
Raddick, M. J., Bracey, G., Gay, P. L., Lintott, C. J., Murray, P., Schawinski, K., . . Vandenberg, J. (2010). Galaxy Zoo: Exploring the motivations of citizen science volunteers. Astronomy Education Review, 9(1), 010103010118. doi: 10.3847/aer2009036

Schneps, M. P. (1989). A private universe [video]. San Francisco, CA: Astronomical Society of the Pacific.

Slater, S. J., Schleigh, S. P., \& Stork, D. J. (2015). Analysis of individual Test Of Astronomy STandards (TOAST) item responses. Journal of Astronomy \& Earth Sciences Education, 2(2).

Slater, S. J., Slater, T. F., Heyer, I., \& Bailey, J. M. (2015). Conducting astronomy education research: An astronomer's guide (2nd ed.). Hilo, HI: Pono Publishing.

Slater, S. J. (2014). The development and validation of the Test Of Astronomy STandards (TOAST). Journal of Astronomy \& Earth Sciences Education, 1(1), 1-22.

Slater, T. F. (1993). The effectiveness of a constructivist epistemological approach to the astronomy education of elementary and middle level in-service teachers. (Ph.D. dissertation), University of South Carolina, Columbia, SC.

Slater, T. F. (2008). The first big wave of astronomy education research dissertations and some directions for future research efforts. Astronomy Education Review, 7(1), 1-12. doi: 10.3847/AER2008001

Slater, T. F. (2014). Editor's Note: JAESE's initial aim, scope and business model. Journal of Astronomy \& Earth Sciences Education, 1(1), i-ii.

Targan, D. M. (1988). The assimilation and accommodation of concepts in astronomy. (Ph.D. dissertation), University of Minnesota, Minneapolis.

Wallace, C. S. (2011). An investigation into introductory astronomy students' difficulties with cosmology, and the development, validation, and efficacy of a new suite of cosmology lecture-tutorials. (Ph.D. dissertation), University of Colorado Boulder, Boulder, CO.

Williamson, K. E. (2013). Development and calibration of a concept inventory to measure introductory college astronomy and physics students' understanding of Newtonian gravity. (Ph.D. dissertation), Montana State University, Bozeman, MT.

Williamson, K. E., \& Willoughby, S. (2012). Student understanding of gravity in introductory college astronomy. Astronomy Education Review, 11(1), 010105-010126. doi: 10.3847/AER2011025

Williamson, K. E., Willoughby, S., \& Prather, E. E. (2013). Development of the Newtonian Gravity Concept Inventory. Astronomy Education Review, 12(1), 010107. doi: 10.3847/AER2012045

Zeilik, M. (2003). Birth of the Astronomy Diagnostic Test: Prototest evolution. Astronomy Education Review, 1(2), 46-52. doi: 10.3847/AER2002005. 


\section{NOTES}

